\title{
Sistem Kendali On/Off Circuit Breaker 150 kV AD20 Tipe 8DN2 di PT. Krakatau Daya Listrik
}

\author{
Endi Permata ${ }^{1}$; Dimas Aditama ${ }^{2}$ \\ ${ }^{1,2}$ Program Studi Pendidikan Vokasional Teknik Elektro, Fakultas Keguruan dan Ilmu Pendidikan \\ Universitas Sultan Ageng Tirtayasa \\ 1endipermata@untirta.ac.id \\ 2platod.d.d.999@gmail.com
}

\begin{abstract}
In the transmission and distribution system at PT. Krakatau Daya Listrik there is a security system created. In this case Circuit Breaker (CB), which is a security installation of the electricity network. $C B$ that is used is GIS (Gas Insulated Switchgear) type where CB uses SF6 gas (Sulfurhexaflouride) as an insulating medium to extinguish the arc. This research itself aims to understand how the 150 kV GIS AD20 On / Off Circuit Breaker process control system at PT. Krakatau Daya Listrik and how the work processes, instrumentation, advantages and disadvantages and maintenance of the $150 \mathrm{kV}$ GIS AD20 Circuit Breaker at PT. Krakatau Electric Power. Using research methods directly in the field with interviews and analysis. The results of this study are in the form of an understanding of $C B$ operating systems that can be turned on both locally and via remote control and also the results of routine $C B$ maintenance as an indication of the appropriateness of the equipment for operation so that from the associated analysis can be known the strengths and weaknesses of the device, especially the circuit breaker type GIS.
\end{abstract}

Keywords: Sulfurhexafluoride, Control System, Transmission and Distribution

\begin{abstract}
ABSTRAK
Pada sistem transmisi dan distribusi di PT. Krakatau Daya Listrik terdapat suatu sistem pengamanan yang dibuat. Dalam hal ini adalah Circuit Breaker (CB), yang merupakan suatu instalasi pengamanan terhadap jaringan listrik. CB yang digunakan berjenis GIS (Gas Insulated Switchgear) dimana CB ini menggunakan gas SF6 (Sulfurhexaflouride) sebagai media isolator untuk memadamkan busur api. Penelitian ini sendiri bertujuan untuk, memahami bagaimana sistem kendali proses On/Off Circuit Breaker 150 kV GIS AD20 di PT. Krakatau Daya Listrik dan bagaimana proses kerja, instrumentasi, keunggulan dan kelemahan serta perawatan Circuit Breaker 150 kV GIS AD20 di PT. Krakatau Daya Listrik. Menggunakan metode penelitian langsung di lapangan dengan wawancara dan analisa. Hasil dari penelitian ini adalah berupa pemahaman mengenai sistem operasi CB yang dapat dinyalakan baik dari lokal maupun via remote control dan juga hasil dari perawatan rutin CB sebagai indikasi layak tidaknya alat untuk operasi sehingga dari analisa terkait dapat diketahui keunggulan dan kelemahan alat terutama circuit breaker yang berjenis GIS.
\end{abstract}

Kata kunci: Sulfurhexafluoride, Sistem Kendali, Transmisi dan Distribusi 


\section{Energi dan Kelistrikan: Jurnal Ilmiah}

Vol. 12, No. 1, Januari - Juni 2020, P-ISSN 1979-0783, E-ISSN 2655-5042

https://doi.org/10.33322/energi.v12i1.920

\section{PENDAHULUAN}

PT. Krakatau Daya Listrik adalah salah satu perusahaan pembangkit listrik di Indonesia. Dengan menggunakan sistem pembangkit PLTU dan PLTGU PT. Krakatau Daya Listrik dapat menghasilkan listrik dengan kapasitas 400 MW dan 120 MW. PT. Krakatau Daya Listrik menyuplai kebutuhan energi listrik mulai dari perusahaan lain, terutama untuk kawasan Krakatau Industri Estate Cilegon (KIEC), dan untuk masyarakat umum yang bertempat tinggal di sekitar kawasan industri Krakatau Steel. PT. Krakatau Daya Listrik juga terinterkoneksi dengan Perusahaan Listrik Negara (PLN) dalam penyediaan tenaga listrik. Dalam penyediaan tenaga listrik tersebut suatu sistem transmisi dibutuhkan dan dalam sistem tersebut tentunya dibutuhkan banyak hal seperti pengaman, komponen, hingga hal terkait lainnya yang mana memiliki tujuan untuk dapat mentransmisikan tenaga listrik sampai kepada konsumen dengan sebaik mungkin sehingga keuntungan kerja dicapai, selain itu pula mewujudkan visi dan misi perusahaan.

Pada sistem transmisi dan distribusi tersebut suatu sistem pengamanan dibuat. Dalam hal ini adalah Circuit Breaker (CB), yang merupakan suatu instalasi pengamanan terhadap jaringan listrik. Jenis-jenis CB pun berbeda-beda dan bermacam-macam tergantung pada kebutuhan jaringan yang dilayaninya. Dengan sistem jaringan listrik yang berbeda-beda nilai tegangannya, dimana diketahui untuk menghindari rugi daya dalam proses pengiriman energi ke pelanggan maka nilai tegangan dari sumber dinaikan sampai ke nilai $500 \mathrm{kV}$, jenis CB pun berbeda. Pada tegangan yang diamati penulis saat melaksanakan penelitian di PT. Krakatau Daya Listrik CB yang digunakan berjenis GIS (Gas Insulated Switchgear) dimana CB ini menggunakan gas SF6 (Sulfurhexaflouride) sebagai media isolator untuk memadamkan busur api dimana nominal tegangan operasi adalah $150 \mathrm{kV}$.

Karena CB ini beroperasi untuk mengamankan jalur tegangan $150 \mathrm{kV}$ seperti yang ditemui di PT. Krakatau Daya Listrik maka proses untuk alat ini agar beroperasi dengan baik perlu dikontrol dan diawasi. Sistem kendali yang terdapat dalam CB ini menarik untuk dibahas sebagai perbedaan pemahaman CB yang sering penulis jumpai dengan CB yang berada di PT. Krakatau Daya Listrik yang nominal tegangannya cukup besar.

Adapun tujuan yang hendak dicapai dalam pelaksanaan penelitian ini diantaranya:

1. Bagaimana sistem kendali proses On/Off Circuit Breaker $150 \mathrm{kV}$ GIS AD20 di PT. Krakatau Daya Listrik.

2. Bagaimana proses kerja, instrumentasi, keunggulan dan kelemahan serta perawatan Circuit Breaker 150 kV GIS AD20 di PT. Krakatau Daya Listrik.

Penelitian ini dilakukan untuk mengetahui tingkat kualitas dan kelayakan CB. Perawatan CB ini sendiri dilakukan dalam periode 1 tahun sekali yang tentunya ditujukan untuk menjaga kualitas pelayanan dan energi listrik perusahaan dan CB itu sendiri. Dari penelitian ini diharapkan diketahui tingkat kelayakan CB terkait sehingga dapat diambil tindakan selanjutnya yang bergantung dari datadata yang ditemui.

\section{METODE/PERANCANGAN PENELITIAN}

Metode penelitian yang digunakan pada penelitian dan seluruh kegiatan ini terdiri dari:

1. Teknik Pengumpulan data: Metode pengumpulan data merupakan strategi yang ditempuh untuk mengambil data lapangan. Data-data dikumpulkan dalam seluruh kegiatan menggunakan metode wawancara dan studi langsung di lapangan. Data dikumpulkan selama kurang lebih satu bulan di industri terkait. Data yang diambil berupa diagram alat untuk memahami cara kerja serta hasil perawatan alat untuk mengetahui kualifikasi dan kelayakan alat tersebut. 
2. Studi wawancara: Dilakukan dengan melakukan wawancara langsung terhadap karyawankaryawan terkait yang ahli dalam bidangnya sehingga permasalahan yang ada bisa dicari jalan keluarnya pula menambah masukan yang benilai kepada penelitian ini. Wawancara dilakukan selama kurang lebih satu bulan selama kegiatan berlangsung. Hal ini dilakukan untuk menemukan solusi dan materi yang sebaik mungkin sehingga kualitas alat dapat dipahami.

3. Studi Literatur: Dilakukan dengan cara mempelajari teori-teori yang mendukung pemecahan masalah baik dari jurnal, buku maupun penelitian yang sejenis. Sehingga dari kegiatan lapangan pula didukung dengan literatur yang relevan.

4. Teknik Analisis: Analisis data dilakukan dengan metode deskriptif kualitatif. Data yang sudah diambil dan diterima dari kegiatan dideskripsikan secara kualitas dengan parameterparameter yang ditentukan melalui syarat kelayakan operasi dari industri. Adapun variabelvariabel yang masuk dalam pengamatan berupa: (a) Tekanan gas $\mathrm{SF}_{6}$, (b) Tekanan hidrolik sistem.

\subsection{Sistem Kendali}

Sistem kendali menurut Norman S. Nice [2] pada halaman 2, yakni, Sistem kontrol terdiri dari subsistem dan proses (atau instalasi) yang dirakit untuk tujuan memperoleh output yang diinginkan dengan kinerja yang diinginkan. Meskipun teori kontrol sering memberikan panduan yang bermanfaat bagi perancang dalam semua aspek desain yang disebutkan di atas, itu hanya memberikan jawaban eksplisit untuk proses awal [9] hal 24. Eman Kamel mendefinisikan sistem kontrol sebagai perangkat atau set struktur yang dirancang untuk mengelola, memerintahkan, mengarahkan, atau mengatur perilaku perangkat atau sistem lain. Seluruh sistem kontrol dapat dilihat sebagai proses multivariabel yang memiliki sejumlah input dan output yang dapat mempengaruhi perilaku proses [1]. Jenis-Jenis Sistem Kendali terdiri dari, Sistem Kendali Terbuka (Open-loop). Mengutip dari buku Katsuhiko Ogata hal 8. Sistem Kontrol Loop Terbuka. Sistem-sistem di mana output tidak berpengaruh pada aksi kontrol disebut sistem kontrol loop terbuka. Dan Sistem Kendali Tertutup (Closed-loop). Sistem kendali closed-loop memiliki jenis-jenis berbeda, dimana sistem kendali di sini terbagi menjadi sistem kendali open dan closed-loop. Dalam closed loop terdapat feedback-loop sebagai suatu sistem juga dapat termasuk menjadi dalam bagian sistem kontrol closed-loop [3].

\subsection{Circuit Breaker (CB)}

Pemutus (PMT). Mengutip dari pedoman PMT dari PLN [4] dan berdasarkan IEV (International Electrotechnical Vocabulary) 441-14-20 disebutkan bahwa Circuit Breaker (CB) atau Pemutus Tenaga (PMT) merupakan peralatan saklar/switching mekanis, yang mampu menutup, mengalirkan dan memutus arus beban dalam kondisi normal serta mampu menutup, mengalirkan (dalam periode waktu tertentu) dan memutus arus beban dalam kondisi abnormal/gangguan seperti kondisi hubung singkat (short circuit). Sedangkan definisi PMT berdasarkan IEEE C37.100:1992 (Standard definitions for power switchgear) adalah merupakan peralatan saklar/switching mekanis, yang mampu menutup, mengalirkan dan memutus arus beban dalam kondisi normal sesuai dengan ratingnya serta mampu menutup, mengalirkan (dalam periode waktu tertentu) dan memutus arus beban dalam spesifik kondisi abnormal/gangguan sesuai dengan ratingnya.

Pemisah (PMS). Disconnecting switch atau pemisah (PMS) adalah peralatan pada sistem tenaga listrik yang berfungsi sebagai sakelar pemisah yang dapat memutus dan menyambung rangkaian dengan arus, yang biasanya dipakai ketika dilakukan perawatan atau perbaikan pada suatu alat yang mengandung PMS tersebut. PMS terletak di antara sumber tenaga listrik dan PMT serta di 


\section{Energi dan Kelistrikan: Jurnal Ilmiah}

Vol. 12, No. 1, Januari - Juni 2020, P-ISSN 1979-0783, E-ISSN 2655-5042

https://doi.org/10.33322/energi.v12i1.920

antara PMT dan beban. Sakelar pemisah hanya boleh dioperasikan dalam kondisi sistem mati dan bertegangan tetapi tanpa beban [5].

\subsection{Gas Insulated Switchgear (GIS)}

Sebagaimana suatu sistem GIS adalah salah satu bagian penting dalam sistem transmisi dan distribusi. Dalam hal ini adalah sistem proteksi sistem. GIS $150 \mathrm{kV}$ dengan merek Siemens 8DN2 di PT. Krakatau Daya Listrik berfungsi sebagai pengaman sistem transmisi dan distribusi jaringan milik PT tersebut. Mengutip dari jurnal Sandra Aditya Kurniawan, Gas Insulated Switchgear adalah sistem koneksi dan jaringan listrik pemutus dikemas dalam tabung non-ferrous dan menggunakan bahan sulfurhexaflouride gas (SF6) sebagai media isolasi. SF6 gas memiliki properti elektronegatif yang memiliki fungsi untuk menghambat busur yang mungkin terjadi ketika operasi switchgear [6].

1. Komponen Circuit Breaker $150 \mathrm{kV}$ Tipe 8DN2

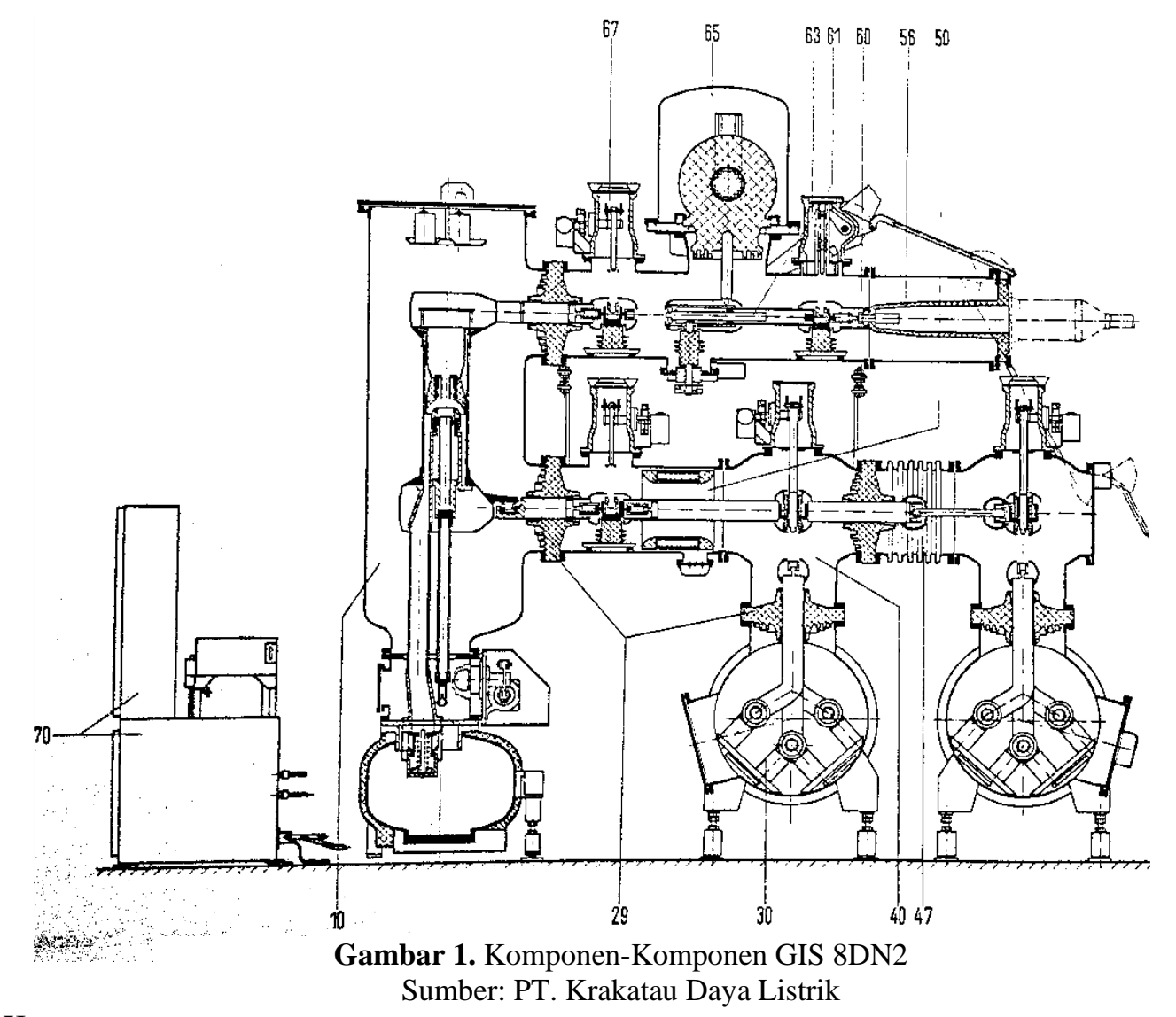

Keterangan:

10. Circuit Breaker Pole, merupakan bagian circuit breaker pada switchgear ini yang mana menggunakan gas SF6 untuk memadamkan busur api ketika proses On/Off sedang berlangsung.

29.Bushings, material isolator yang memisahkan bus main conductor dengan body switchgear.

30. Bus Conductor, yang berkerja sebagai konduktor bus pada sistem tenaga listrik.

40. Bus Isolator, berfungsi sebagai isolator utama pemisah bus conductor dengan jaringan.

47. Temperatur Compensating bellows.

50. Current Transformers, berfungsi sebagai trafo pengukur arus dan sistem proteksi pada switchgear.

56. Cable Sealing End, terminal akhir/awal kabel tegangan tinggi dari/ke switchgear. 
60. Terminal Assembly.

61. Cable Isolator, berfungsi sebagai pemisah atau isolator dari kabel ke switchgear.

63. Make-proof Earthing Switch.

67. Work-in-progress Earthing Switch, bagian nomor 63 dan 67 termasuk kedalam bagian pentanahan.

65. Voltage Transformer, berfungsi sebagai trafo pengukur tegangan pada switchgear.

70.Control Panel, panel kontrol switchgear berfungsi untuk mengoperasikan secara manual, kontrol proteksi dan indikator dari switchgear.

\section{Prinsip Kerja GIS Siemes 8DN2 $150 \mathrm{kV}$}

Prinsip kerja switchgear 150 kV PT Krakatau Daya Listrik dengan membagi tegangan yang akan ditransmisikan kepada konsumen melaui substation-substation atau gardu induk dan juga digunakan untuk Interkoneksi dengan PT PLN. Pada switchgear terdapat dua buah busbar utama yang digunakan bersamaan dengan kopling. Switchgear ini berada setelah transformator AT dari generator yang menaikkan tegangan dari $10,5 \mathrm{kV}$ menjadi $150 \mathrm{kV}$ dan substation beban PT Krakatau Daya Listrik. PMT tersusun dari Kompartemen tekanan ganda yang terdiri dari Kompartemen tekanan tinggi dengan tekanan nominal sebesar 17,7 bar pada suhu $200^{\circ} \mathrm{C}$ dan tekanan rendah dengan tekanan nominal 2,75 bar pada suhu yang sama.

\subsection{Gas SF6}

Sulfurhexafluoride (SF6) adalah gas dialektrik yang sangat baik untuk aplikasi daya tegangan tinggi. SF6 adalah gas yang tidak beracun dan tidak berwarna, dengan konduktivitas suhu yang bagus dan kerapatan mendekati 5 kali dari udara $(6.14 \mathrm{~kg} / \mathrm{m} 3)$. Gas ini juga tidak bereaksi dengan materialmaterial yang biasa dipakai pada breaker tegangan tinggi [7].

\subsection{Sistem Hidrolik}

Sistem hidrolik merupakan suatu bentuk perubahan atau pemindahan daya dengan menggunakan media penghantar berupa fluida cair untuk memperoleh daya yang lebih besar dari daya awal yang dikeluarkan. Dimana fluida penghantar ini dinaikkan tekanannya oleh pompa pembangkit tekanan yang kemudian diteruskan ke silinder kerja melalui pipa-pipa saluran dan katupkatup. Gerakan translasi batang piston dari silinder kerja yang diakibatkan oleh tekanan fluida pada ruang silinder dimanfaatkan untuk gerak maju dan mundur maupun naik dan turun sesuai dengan pemasangan silinder yaitu arah horizontal maupun vertikal [8].

\section{HASIL DAN PEMBAHASAN}

\subsection{Circuit Breaker $150 \mathrm{kV}$ GIS (Gas Insulated Switchgear)}

Gas Insulated Switchgear (GIS) adalah suatu sistem penghubung dan pemutus jaringan listrik yang berupa suatu alat yang berbentuk tabung non-ferro dan menggunakan gas sulfurhexafluoride (SF6) sebagai media isolasi. GIS ini diterapkan dan digunakan pada PT Krakatau Daya Listrik sebagai bagian penting dari sistem transmisi dan distribusi juga pembangkit. Seperti yang diketahui GIS beroperasi untuk menghubungkan sistem transmisi bertegangan tinggi dan juga mengamankannya, yang dalam hal ini beroperasi pada rating tegangan $150 \mathrm{kV}$ hingga $170 \mathrm{kV}$. Untuk menunjang proses yang efektif dan efisien makan switchgear ini membutuhkan berbagai sistem proteksi seperti indikator gas, sistem pentanahan hingga pengatur tekanan gas SF6. Hal ini dilakukan untuk memastikan jumlah pasokan listrik, kestabilan sistem dan juga untuk menjamin keselamatan 


\section{Energi dan Kelistrikan: Jurnal Ilmiah}

Vol. 12, No. 1, Januari - Juni 2020, P-ISSN 1979-0783, E-ISSN 2655-5042

https://doi.org/10.33322/energi.v12i1.920

dan kesehatan perkerja. Switchgear sendiri merupakan suatu sistem gabungan dari pemisah dan pemutus.

\subsection{Sistem Kendali On/Off Circuit Breaker $150 \mathrm{kV}$ AV20 Tipe 8DN2 di PT. Krakatau Daya Listrik}

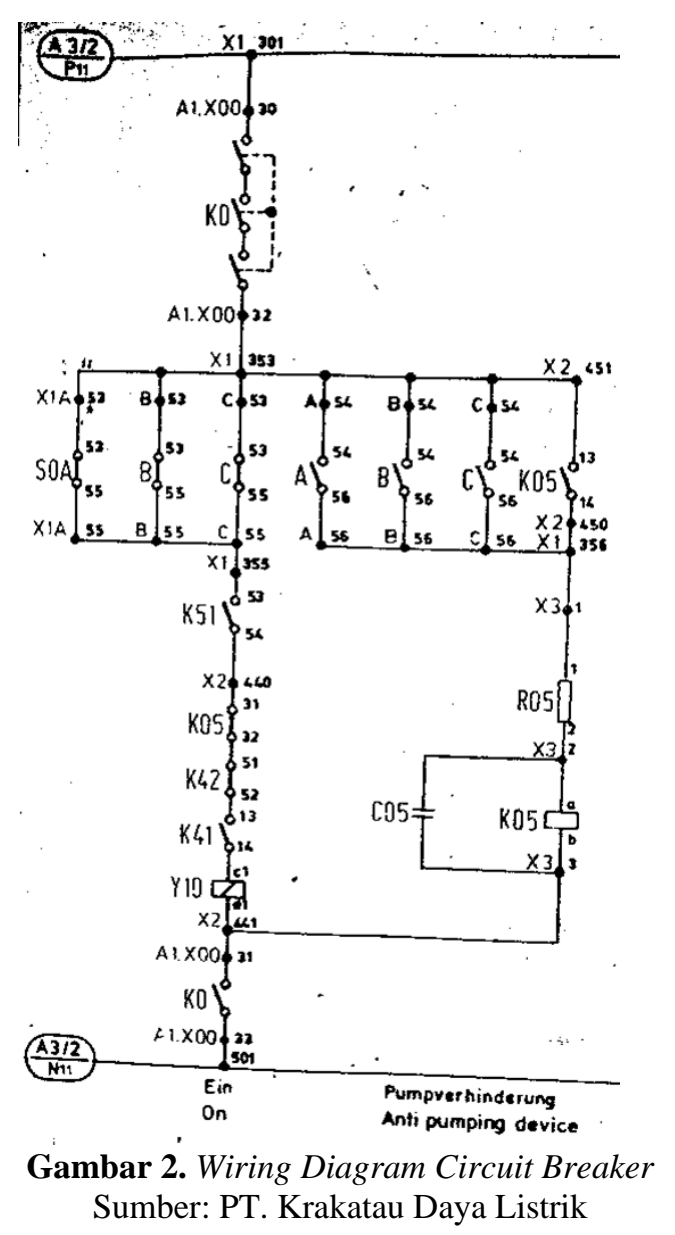

Secara umum pada sistem kendali on/off CB 8DN2 dapat dilakukan secara langsung dan tidak langsung. Yang dimaksud di sini adalah penyalaan CB dapat dilakukan melalui alat atau melalui remote control. Untuk penyalaan manual dapat dilakukan dengan menekan tombol secara manual dari switchgear sehingga alat CB dapat melakukan proses dengan mekanisme sistem hidrolik.

Keterangan Gambar 2:

K0: Kontaktor untuk operasi ON CB

K51: General lockout, merupakan sistem proteksi gas SF6 pada bagian circuit breaker yang berfungsi untuk memblok pengoperasian ON atau OFF sistem GIS $150 \mathrm{kV}$

K05: Anti Pumping Devices, merupakan sistem proteksi yang mengontrol tekanan pada sistem hidrolik dan SF6. Circuit Breaker tidak akan bisa dilakukan pengoperasian ON berulang apabila pada sistem hidrolik dan SF6 belum mencapai tekanan standard

K41: Min. Pressure lockout, merupakan pengaman tekanan pada sistem hidrolik apabila tekanan kurang dari batas yang telah ditentukan dalam sistem ini tekanan minimalnya adalah 155-5 bar 
K42: Low of nitrogen, akan bekerja apabila nilai tekanan total hidrolik dibawah rata-rata dalam sistem kontrol $150 \mathrm{kV}$ ini, tekanan hidrolik rata-ratanya adalah 190-5 bar, yang diperoleh dari nitrogen sebesar 100 bar dan kekurangannya dipenuhi oleh hidrolik

S0A, B, C: Auxilliary contact, tempat posisi switchgear atau circuit breaker saat itu (ON/OFF)

Y20A, B, C: Magnetic coil untuk tripping atau OFF circuit breaker

Y10: Drive Mechanism untuk aktuator CB yang digunakan untuk menyalakan CB

Melihat dari Gambar 2 di atas, kontaktor K0 merupakan sebuah kontaktor atau push button untuk mengoperasikan on CB, kontaktor K51 merupakan general lockout yang akan menutup rangkaian jika semua kontrol tekanan telah sesuai dengan yang telah ditentukan, sedangkan K41 merupakan minimum pressure yang mengontrol tekanan pada sistem hidrolik, dalam hal ini tekanannya di atur pada rentang 155-5 bar, jika tekanan kurang dari batas minimal makan K41 akan trip. CB ini dapat berhenti beroperasi atau dihentikan secara manual maupun remote atau lokal, dan dapat juga berhenti beroperasi dikarenakan gangguan atau trip. Ketika akan dilakukan perawatan atau perbaikan pada sistem, CB dapat dihentikan operasinya secara manual, dengan menutup K0 yang merupakan kontaktor untuk pengoperasian OFF pada Y20. Untuk melakukan secara remote atau lokal, dilakukan dengan mengoperasikan K1. Trip dapat terjadi jika CB mendapat input dari panel HN01 dan HK6 merupakan panel proteksi kombinasi yang terdiri dari differensial relay, distantance relay dan over current relay.

Pada gambar di atas dapat dilihat wiring diagram dari sistem kendali CB $150 \mathrm{kV}$ 8DN2. Pada saat K0A ditekan kontak 37-38 akan tertutup sehingga arus dapat mengalir dan melewati kontaktor K1. Sesuai dengan spesifikasi GIS dimana K1 mendapatkan arus maka kontak yang terkait akan berubah, kontak 13-14, 23-24, 33-34 dan 43-44 yang dalam keadaan terbuka (NO) akan menjadi keadaan tertutup (NC). Pada keadaan OFF kontak-kontak K51 berada dalam keadaan terbuka, namun pada keadaan ON kontak-kontak K51 berada pada keadaan tertutup. Dan keadaan inilah keadaan dimana CB dalam keadaan tertutup atau menyala dimana CB mengalirkan arus melalui busbarnya kepada sistem transmisi dan distribusi PT KDL.

Sementara pada posisi pembukaan dapat dilakukan dengan jarak jauh begitu pula dengan pada proses penutupan. Terlihat pada gambar bahwa rele proteksi HK6 dan HN01 langsung menuju kontak K51 tanpa melewati kontak lainnya, dimana berarti jika ada gangguan drop tegangan maka arus akan langsung mengalir ke kumparan untuk mengaktifkan pelepasan CB. S0A, S0B dan S0C merupakan moving contact dimana pada keadaan GIS tidak berkerja, kontak-kontak ini akan tetap menutup. Setelah itu, arus akan dapat mengalir melalui kontak-kontak yang telah tertutup tersebut, Kemudian setelah itu akan melewati Y20A, Y20B, dan Y20C dimana komponen ini merupakan kumparan/selenoid atau tripping spring yang mengistruksikan $\mathrm{CB}$ untuk membuka kontakkontaknya dan memutuskan aliran listrik pada switchgear.

\subsection{Perawatan Circuit Breaker 150 kV di PT. Krakatau Daya Listrik}

Dalam pelaksanaan perawatan CB GIS 150 kV PT Krakatau Daya Listrik yang dilakukan penulis ada dua tipe perawatan yang perlu digaris bawahi yakni perawatan minor dan major, dimana perawatan yang penulis ikut serta di dalamnya adalah perawatan tipe minor visual dimana dilakukan perawatan ringan terhadap CB $150 \mathrm{kV}$. Perawatan ini seperti mengecek tingkat tekanan gas SF6, tekanan oli, pelumasan kontak-kontak kontaktor dan perawatan alat seperti pembersihan dari debu menggunakan manju. Berikut ini adalah pengecekan dan pengujian pada perawatan CB $150 \mathrm{kV}$ 8DN2 AD 20 pada hari rabu tanggal 3 Juli 2019 yang ditunjukan oleh Tabel 1: 
Tabel 1. Maintenance CB 150 kV 8DN2 AD20 Tanggal 3 Juli 2019

\begin{tabular}{|c|c|c|c|c|c|c|c|}
\hline \multirow{2}{*}{ No. } & \multirow{2}{*}{ Uraian Pengujian } & \multicolumn{2}{|c|}{ Setting Instrument } & \multicolumn{2}{|c|}{$\begin{array}{c}\text { Standar Tekanan } \\
\text { (bar) }\end{array}$} & \multirow{2}{*}{$\begin{array}{l}\text { Hasil Cek } \\
\quad \text { (bar) }\end{array}$} & \multirow{2}{*}{ Ket. } \\
\hline & & $\begin{array}{l}\text { 8DN2 } \\
\text { (old) }\end{array}$ & $\begin{array}{l}\text { 8DN2 } \\
\text { (new) }\end{array}$ & $\begin{array}{l}\text { 8DN2 } \\
\text { (old) }\end{array}$ & $\begin{array}{l}8 \mathrm{DN} 2 \\
(\text { new) }\end{array}$ & & \\
\hline & \multicolumn{7}{|l|}{ Hydraulic Pressure System } \\
\hline 1 & Hydraulic Motor ON & B 43 & $\begin{array}{l}\text { B1 WS- } \\
\text { SW-GN }\end{array}$ & 186 & 313 & 186 & \\
\hline 2 & $\begin{array}{c}\text { Min Pressure Lockout } \\
\text { ON }\end{array}$ & B 41 & $\begin{array}{c}\text { B20R-GE- } \\
\text { BR }\end{array}$ & 153 & 273 & 153 & \\
\hline 3 & Loss Of Nitrogen & B 5 & $\begin{array}{c}\text { B10R-GE- } \\
\text { BR }\end{array}$ & 220 & 345 & 210 & \\
\hline 4 & Nitrogen & - & - & 110 & 200 & 110 & \\
\hline & \multicolumn{7}{|l|}{ SF6 Pressure System } \\
\hline 5 & Compressor Motor ON & B 60 & $\begin{array}{l}\text { B2 WS- } \\
\text { SW-GN }\end{array}$ & 17,2 & 7 & 17,2 & \\
\hline 6 & Compressor Motor OFF & - & $\begin{array}{l}\text { B2 WS- } \\
\text { SW-GN }\end{array}$ & 17,7 & 7 & 18,5 & \\
\hline 7 & Loss Of-HP SF6 Drop & В 562 & $\begin{array}{l}\text { B4SW- } \\
\text { B2-WS }\end{array}$ & 15,3 & 6,2 & 15,1 & \\
\hline 8 & General Lock Out & B512 & $\begin{array}{l}\text { B4RT- } \\
\text { OR-GE }\end{array}$ & 14,1 & 0,2 & 14,1 & \\
\hline 9 & $\begin{array}{c}\text { CB. Blocking } \\
\text { (Generator Feeder's } \\
\text { Only) } \\
\end{array}$ & В 750 & 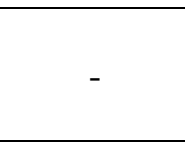 & 15,3 & - & - & \\
\hline$\#$ & $\begin{array}{c}\text { Low Pressure SF6 } \\
\text { Failed }\end{array}$ & B 53 & - & 2 open & $\begin{array}{c}2,4 \\
\text { closed }\end{array}$ & - & \\
\hline \# & $\begin{array}{c}\text { Min Pressure SF6 For } \\
\text { No Load Operating }\end{array}$ & & & & 4,5 bar & - & \\
\hline
\end{tabular}

Dimana seperti yang dapat di lihat dari Tabel 1. di atas bahwasannya alat masih dalam kategori layak operasi. CB 8DN2 yang diuji dan dicek kelayakannya menunjukkan hasil yang uji yang tidak terlalu jauh dengan nilai standar. Alat CB $150 \mathrm{kV}$ yang dicek menggunakan standar 8DN2 old dengan tekanan hydraulic saat motor dalam posisi on memiliki selisih 0 antara hasil uji dengan standar, ada tekanan minimal dalam keadaan lockout on memiliki selisih 0 antara hasil uji dengan standar tekanan, nitrogen loss yang terukir memiliki selisih 10 bar dari tekanan standar yang dalam hal ini masih terbilang normal, untuk tekanan gas nitrogen memiliki selisih 0 dengan tekanan standar. Untuk tekanan gas SF6 pada kompressor motor sedang dalam posisi on hanya memiliki selisih 0,1 bar dengan tekanan standar gas, begitu pula pada pada saat kondisi motor off yang memiliki selisih 0,8 bar dengan tekanan standar yang mana masih dalam kategori layak, pada HP drop gas SF6 memiliki selisih 0,2 dengan tekanan standar dan pada general lockout memiliki selisih 0 bar dari tekanan standar alat. Sehingga dari pengujian ini alat masih dalam kategori layak operasi.

\section{KESIMPULAN DAN SARAN}

Dari data-data yang telah diperoleh dan hasil analisis yang dilakukan baik melalui pustaka dan langsung dapat diambil beberapa kesimpulan, diantaranya adalah sebagai berikut:

1) Sistem kendali proses On/Off Circuit Breaker $150 \mathrm{kV}$ GIS AD20 di PT. Krakatau Daya Listrik dilaksanakan dan bertujuan untuk mengendalikan alat yakni CB GIS yang menangani tegangan transmisi dari trafo pembangkit sebesar $150 \mathrm{kV}$ untuk ke konsumen 
PT. Krakatau Daya Listrik. Proses kendali sendiri adalah suatu sistem pengendalian variabel input dan variabel output pada suatu sistem kerja atau proses dalam hal ini inputnya berupa sensor tekanan gas SF6 dan sensor-sensor lainnya kemudian aktuator/outputnya berupa pompa hidrolik dimana bertujuan untuk memperoleh hasil sesuai dengan yang diinginkan yakni sistem kerja yang mampu melakukan on dan off pada CB $150 \mathrm{kV}$ dengan media gas SF6 sebagai pemadam busur api dan media isolasi listrik.

2) Proses kerja CB 150 kV GIS AD20 di PT. Krakatau Daya Listrik dapat dihentikan operasinya secara manual, dengan menutup K0A yang merupakan kontaktor untuk pengoperasian OFF pada Y20. Untuk melakukan secara remote atau lokal, dilakukan dengan mengoperasikan K1. Trip dapat terjadi jika CB mendapat input dari panel HN01 dan HK6 merupakan panel proteksi kombinasi yang terdiri dari differensial relay, distantance relay dan over current relay. Instrumentasi pada CB ini memiliki beberapa komponen utama pengendali diantaranya, Circuit Breaker Pole, Temperatur Compensating, Current Transformers, Earthing Switch, Voltage Transformer, dan Control Panel.

\section{UCAPAN TERIMAKASIH}

Penulis mengucapkan terimakasih kepada PT. Krakatau Daya Listrik yang telah memberikan izin untuk pelaksanaan penelitian serta kepada seluruh pihak lain yang terkait.

\section{DAFTAR PUSTAKA}

[1] Kamel, Kamel Khaled and Eman. (2014). Programmable Logic Controllers Industrial Control. New York: McGraw-Hill.

[2] Nice, Norman S. (2011). Control System Engineering Sixth Edition. United States of America: John Willey and Sons Inc.

[3] Ogata, Katsuhiko. (2010). Modern Control Engineering Fifth Edition. United States of America: Prentice Hall.

[4] PLN. (2014). Buku Pedoman Pemeliharaan Pemutus Tenaga (Pmt). Jakarta Selatan: PT PLN (Persero).

[5] (1995). PLN Operasi \& Pemeliharaan Jaringan Distribusi.

[6] Sandra Aditya Kurniawan, dkk. (2012). "Perawatan Gas Insulated Switchgear 500 kV Pada PT. KPJB (PT. KOMIPO - Pembangkit Jawa Bali)." 10 halaman.

[7] Setiono, Iman. (2017). "Gas SF 6 (Sulfur Hexa Fluorida) Sebagai Pemadam Busur Api Pada Pemutus Tenaga (PMT) Di Saluran Transmisi Tegangan Tinggi.” METANA. Vol. 13(12) 6 halaman.

[8] Sutimbul, Catur. (2006). Analisis Kerja Mesin Hidrolik Pencetak Paving Dengan Sistem Hand Control Hidrolik Pada Waktu Yang Dibutuhkan Langkah Naik Dan Turun Silinder Hidrolik. Semarang: Universitas Negeri Semarang.

[9] William S. Levine, Dimitrios Hristu-Varsakelis. (2005). Handbook of Networked and Embedded Control Systems. United States of America: Birkha user Boston. 